\title{
Antiretroviral Treatment Adherence and
}

\section{Determinant Factors Among Adult People Infected with Human Immunodeficiency Virus in Eastern Tigray General Hospitals, Northern Ethiopia, 2019}

This article was published in the following Dove Press journal:

HIVIAIDS - Research and Palliative Care

Teklehaimanot Tesfay

Gebreagziabher $\mathbb{D}$

Guesh Teklu Woldemariam (ID

Department of Nursing, College of Medicine and Health Sciences, Adigrat University, Adigrat, Ethiopia
Correspondence: Teklehaimanot Tesfay Gebreagziabher

Tel +25 | $9469 \mid 8227$

Email teklehaimanot.tesfay@adu.edu.et

Guesh Teklu Woldemariam

Tel +25I-940304I 40

Email gueshomt2I@gmail.com
Background: Human immune deficiency virus is a significant cause of morbidity and mortality, especially in developing countries. Globally, about 37.9 million people had HIV/ AIDS in 2018 and 36.2 million people were adults, Moreover, about 770,000 AIDS-related mortality occurred in adult infected people. Appropriate antiretroviral therapy adherence is important to minimize drug resistance, improve virological response, and decrease morbidity and mortality. Researches done in Ethiopia reported knowledge on antiretroviral therapy adherence and determinant factors were limited and the literature was scared. Moreover, the eastern zone of Tigray was inhabited with a highly rural population and this may be a significant facilitator and barrier to ART adherence. According to a census conducted by the central agency of Ethiopia in 2013, the eastern zone of Tigray has a population of 755,343, of whom 395,705 are women and $609,279(80.66 \%)$ are rural inhabitants.

Objective: This study aimed to assess antiretroviral therapy adherence and determinant factors among Adult HIV infected people in eastern Tigray, 2019.

Methods: A cross-sectional study design was conducted from January 1 to June 302019 on 339 adults attending the antiretroviral clinic at eastern Tigray. A systematic random sampling method was used to pick the study samples. Data were collected by a structured questionnaire using face to face interview. P-value $<0.05$ in multivariate analysis was used as a cutpoint for the statistical significance of the association.

Results: About $74.6 \%$ of participants were adhering to antiretroviral therapy. Place of residence $(\mathrm{AOR}=5.13$ (1.63-13.44), social support $(\mathrm{AOR}=2.71$ (1.37-9.74), HIV disclosure $(\mathrm{AOR}=3.32$ (1.43-9.24), free from depression $(\mathrm{AOR}=2.54$ (1.36-9.43) and free from substance use $(\mathrm{AOR}=3.42$ (1.67-10.87) were the factors associated with adherence to antiretroviral therapy.

Conclusion and Recommendation: Drug adherence in eastern Tigray was low and place of residence, social support, HIV disclosure, free from depression and free substance use were the factors associated with ART. So, awareness creation for rural residence, social support, avoidance of depression, and substance use should be strengthened to increase drug adherence.

Keywords: adherence, antiretroviral therapy, Tigray, Ethiopia

\section{Introduction}

Human immune deficiency virus (HIV)/acquired human immune deficiency syndrome (AIDS) is a significant cause of morbidity and mortality, especially in developing countries. ${ }^{1}$ In 2018 , about 37.9 million numbers of people had HIV/ 
AIDS worldwide and about 36.2 million people were adults, moreover, about 770,000 AIDS-related mortality happens in adult people. In 2018, developing countries continued to be the greatest seriously attached continents by HIV/AIDS, which accounted for about $61 \%$ of HIV infections among all age groups worldwide and $94.1 \%$ of new HIV infection cases were among adult groups. ${ }^{2}$ In Ethiopia, the HIV/AIDS incidence rate had started to increase by about $10 \%$, and the prevalence of new cases detected every year rose by $36 \%$ among all age groups and twice among adults, by the year $2008 .^{3}$

Adherence to antiretroviral treatment regimen must be encouraged for continuous suppression of HIV. Moreover, antiretroviral therapy adherence lower than $95 \%$, is related to the progression of biological resistance. Drug-resistant viruses can be limited to their treatment options and increased transmission to other people. ${ }^{1}$ Therefore, appropriate antiretroviral therapy adherence is mandatory to decrease the possibility that drug resistance will develop, to increase virological response, and to decrease disability and death. ${ }^{4}$ However, low antiretroviral therapy adherence leads to the development of AIDS by decreasing the effectiveness of the drug, lowering the CD4 amount, and raising the viral load. Therefore, assessment of antiretroviral therapy adherence is important for a good treatment outcome. $^{5}$

Studies reported that a controversy about the relationship between ART adherence and socio-demographic factors. Few kinds of literature say there is a relationship between socio-demographic characteristics and ART adherence. But, others stated no relationship. Moreover, the researches done in Ethiopia reported knowledge on ART adherence, and determinant factors were limited and related literature was scared. ${ }^{6}$

Moreover, adherence is changing from time to time and from geopolitical zone to another geopolitical zone with their exceptional features of beliefs, socioeconomic status, and access to health care and their attitudes, because, timely change of access to ART services like HIV testing and counseling, a wide distribution of ART treatment. The magnitude and associated factors of adherence differ across geopolitical zones. ${ }^{7}$

The assessment of ART adherence and determinant factors helps to identify major health problems related to ART adherence and for policymakers employed in the HIV/AIDS area for appropriate planning and implementation. Also, it is important to study adherence always because adherence changes from one period of time to another period and varies from geographical location to other geographical locations.

Therefore, this study was aimed to assess ART adherence and its determinant factors among HIV/AIDS adult people in eastern Tigray, Northern Ethiopia. Moreover, the eastern zone of Tigray was inhabited with a highly rural population and this may be a significant facilitator and barrier to ART adherence. According to a census conducted by the central agency of Ethiopia in 2007 E.C or 2013 G.C, the eastern zone of Tigray has a population of 755,343 , of whom 395,705 are women and 609,279 $(80.66 \%)$ are rural inhabitants. ${ }^{8}$

\section{Methods and Materials \\ Study Design, Period, and Setting}

Cross-sectional study design was conducted from January to June 2019, eastern Tigray, northern Ethiopia. This zone has two general hospitals namely Adigrat general hospital and Wukro general hospital, which has a total population of 755,343 , of whom 359,638 are men and $19.34 \%$ are urban residents according to the 2007 national census. Adigrat hospital was found in Adigrat town, which was located $125 \mathrm{~km}$ from Mekelle city, $894 \mathrm{~km}$ from the Addis Ababa city. Adigrat general hospital was launched ART services in 2005 and now it gives service to more than 100,000 people living in the Eastern part of Tigray. More than $3000 \mathrm{HIV/AIDS}$ patients were taking ART treatment by the end of October 2018. Wukro general hospital is found in Wukro town midway between Adigrat and Mekelle.

\section{Study Participants}

All people living with HIV/AIDS (PLWHA) on HAART for at least 3 months, who were above 18 years, and available during the study period.

\section{Sample Size Determination and Sampling Procedure}

The sample size for the study was determined by using the formula for a single population proportion by assuming $5 \%$ marginal error (d), $95 \%$ confidence interval (alpha $=0.05$ ), and the proportion of adherence $(50 \%)$. By considering a correction formula, the total final sample size was 339. Initially, proportionate allocation sampling was used for each general hospital, and then a systematic random sampling technique was used to recruit study 
participants. The first participant was selected by the lottery method, then after every Kth interval was selected.

\section{Data Procedure and Tools}

Data were collected by two trained BSc nurses using a structured questionnaire, which was adapted from literature. ${ }^{6}$ The questionnaire includes social-demographic characteristics (age, sex, education, ethnicity, address, religion, occupation, marital status, social support), socioeconomic characteristics (income), clinical characteristics (depression, substance use, and disclosure of HIV serostatus, WHO clinical staging and drug regimen). The primary data were collected by face to face interviews and secondary data was collected by reviewing the patient's medical charts. Moreover, the validity and reliability of the questionnaire were checked.

\section{Measurements}

Still, there is no standard tool to assess the adherence of ART. Therefore, in this study adherence was measured by three combined indicators. These are self-reported dose adherence, self-reported schedule adherence, and self-reported food adherence. Self-reported dose adherence was defined as the patient's self-report of whether any skip of antiretroviral therapy in the previous seven days. We ask the patient do you skip your pills in the previous seven days. If the response is yes; we ask him/her how many? Percent doses taken over seven days were calculated from the participants' responses. A person was said to be self-reported dose adherent if he/she took $\geq 95 \%$ of the prescribed dose correctly. Self-reported time adherence was defined as when the patient always follows the schedule of instructions provided by the health care providers. We ask the patient have you failed to take any of your medications at the time other than those scheduled by the health care providers in the previous seven days. If the response is yes; we ask him/her how many? The percent of right time taken to medications over seven days were calculated from the participants' response. A person was said to be self-reported time adherent if he/she follow $\geq 95 \%$ of the health care provider schedule instructions correctly. Selfreported food adherence was defined as when the patient always following dietary instructions agreed with the health care providers. A person was said to be self-reported food adherent if he/she took $\geq 95 \%$ of the dietary instruction provided by health care providers correctly. A single patient may be adherent to self-reported dose only and the other may be adherent to self-reported time and food. Therefore, for comparison purposes, a combined adherence measurement was taken from the three adherence measures Therefore, a person was said adherent if he/she took $\geq 95 \%$ of the prescribed dose correctly, always follow schedule instruction, and always follow dietary instructions. This means the person was adherent at least to self-reported dose, time, and food at the same time for $\geq 95 \%$ health care provider instructions. ${ }^{6}$

\section{Data Quality Control}

Before data collection, two-day training had given for two data collectors and one supervisor. To enhance the quality of data, a pretested data collection tool was used. A pretest was conducted in 34 patients attending an ART clinic in Hawzen town, which were not included in the study. The collected data were reviewed and checked for completeness before data entry and incomplete data were removed soon after detection. The questionnaire was initially prepared in English then it was translated into the local language (Tigrigna), by a panel of experts fluent in the language. It was then translated back to English to check for consistencies in the meaning of words by another language expert.

\section{Data Processing and Analysis}

The collected data were checked visually for its completeness and consistency. Then the data were coded, edited, entered, and cleaned by Epi data manager version 4.4.3.1 then it was exported to SPSS (statistical package for social sciences) version 25.0 for statistical analysis. Descriptive statistics (frequency and percentage) were computed. Bivariate logistic regression analysis was performed to identify the association of each independent variable with the outcome variables. The variables which were significant at $\mathrm{p}<0.2$ in bivariate with the outcome variable were selected for multivariate analysis to control confounding and p-value $<0.05$ was used as a cut-point of statistical significance of the association. Multi-collinearity was checked by using a variance inflation factor and tolerance test. Hosmer-Lemeshow test was used to check the fitness of the model. The results were summarized and presented by texts and tables.

\section{Result}

\section{Socio-Demographic Characteristics of the Study Participants}

A total of 339 study participants, who fulfilled the inclusion criteria were included in the study with a response rate of $100 \%$. Among the total study participants, more 
than half $183(53.9 \%)$ were females and the majority 134 (39.52\%) were age between 25-34 years. Of the total study participants $263(77.58 \%)$ permanently living in urban and $76(22.42 \%)$ were living in a rural area. The majority of the study participants $328(96.76 \%)$ were Orthodox and regarding their marital status, 158 (46.6\%) of the entire study participant reported that they were married. Of the total study participants, about 129 $(38.05 \%)$ were unable to read and write, and about 129 $(38.05 \%)$ daily laborers in their occupation. The majority of the respondents $161(47.49 \%)$ reported that they were collected greater than 1000 Birr estimated monthly income and the majority of respondents $242(71.39 \%)$ were living with their parents (Table 1).

\section{Clinical Characteristics of the Study Participants}

According to the WHO disease staging, of the total study participants, $172(50.73 \%)$ of them were stage III and 81 (23.89\%) of stage II during enrollment of ART. The CD4 count for the majority of the study participants was less than 200, which accounts for $172(50.74 \%)$ when treatment started. However, the recent CD4 count for the majority of the study participants was $\geq 500$, which accounts for 167 (49.26\%). Of the total respondents, 220 (64.89\%) had a treatment duration of more than 24 months, whereas $38(11.20 \%)$ had a treatment duration of fewer than 12 months. Regarding the treatment regimen, most of the participants 108 (31.85\%) were currently taking antiretroviral therapy with a regimen of Tenofovir (TDF), Lamivudine (3TC), and Efavirenz (EFV) combination (Table 2).

\section{Adherence to ART and Reasons for Non-} Adherence

ART adherence was assessed by the three indicators. Based on this, $274(80.83 \%)$ of the study participants were adherent based on self-report of missed dose adherence in a one week recall. Two hundred sixty-two (77.28\%) of the study participants always followed the time adherence and 304 (89.67\%) follow food adherence. Therefore, the combined indicator of the dose, time, and food adherence measurement was 253 (74.63\%) $(95 \% \mathrm{CI}$ : 71.277.3\%) (Table 3).

The reasons given for missing drugs simply forgot $46(53.49 \%)$, being far from home $21(24.42 \%)$, being
Table I Socio Demographic and Socioeconomic Characteristics of HIVIAIDS People in Eastern Tigray General Hospitals, Northern Ethiopia, 2019 ( $N=339)$

\begin{tabular}{|c|c|c|}
\hline Variables & Characteristics & Number (\%) \\
\hline Sex & $\begin{array}{l}\text { Male } \\
\text { Female }\end{array}$ & $\begin{array}{l}156(46.1 \%) \\
183(53.9 \%)\end{array}$ \\
\hline Age & $\begin{array}{l}18-24 \\
25-34 \\
35-44 \\
\geq 45\end{array}$ & $\begin{array}{l}16(4.72 \%) \\
134(39.52 \%) \\
129(38.06 \%) \\
60(17.70 \%)\end{array}$ \\
\hline Permanent address & $\begin{array}{l}\text { Urban } \\
\text { Rural }\end{array}$ & $\begin{array}{l}263 \text { (77.58\%) } \\
76(22.42 \%)\end{array}$ \\
\hline Ethnicity & $\begin{array}{l}\text { Tigray } \\
\text { Amhara }\end{array}$ & $\begin{array}{l}30 \mathrm{I}(88.8 \%) \\
38 \text { (11.2\%) }\end{array}$ \\
\hline Religion & $\begin{array}{l}\text { Orthodox } \\
\text { Others* }\end{array}$ & $\begin{array}{l}328(96.76 \%) \\
\text { II (3.24\%) }\end{array}$ \\
\hline Marital status & $\begin{array}{l}\text { Married } \\
\text { Single } \\
\text { Widowed } \\
\text { Divorced }\end{array}$ & $\begin{array}{l}158(46.6 \%) \\
53(15.64 \%) \\
53(15.64 \%) \\
75(22.12 \%)\end{array}$ \\
\hline Educational status & $\begin{array}{l}\text { Unable to read and write } \\
\text { Elementary } \\
\text { Secondary } \\
>12\end{array}$ & $\begin{array}{l}129(38.05 \%) \\
129(38.05 \%) \\
59(17.4 \%) \\
22(6.5 \%)\end{array}$ \\
\hline Occupational status & $\begin{array}{l}\text { Governmental employee } \\
\text { Merchant } \\
\text { House wife } \\
\text { Daily laborer } \\
\text { Have no job } \\
\text { Others }\end{array}$ & $\begin{array}{l}38(11.21 \%) \\
32(9.44 \%) \\
38(11.21 \%) \\
129(38.05 \%) \\
59(17.45 \%) \\
43(12.68 \%)\end{array}$ \\
\hline Average monthly income & $\begin{array}{l}\leq 500 \\
501-999 \\
\geq 1000\end{array}$ & $\begin{array}{l}97(28.62 \%) \\
81(23.89 \%) \\
161(47.49 \%)\end{array}$ \\
\hline Social support & $\begin{array}{l}\text { Alone } \\
\text { Family }\end{array}$ & $\begin{array}{l}97(28.61 \%) \\
242(71.39 \%)\end{array}$ \\
\hline
\end{tabular}

Note: *Indicates Muslim and Protestant.

busy $11(12.79 \%)$, and $8(9.3 \%)$ both fear of side effects of medication and feeling sick.

When we see the descriptive relationship of sociodemographic characteristics with the reasons for nonadherence; of the total non-adhered patients whose reason was due to forgetting, about 25 (54.3\%), 37 (80.4\%) and $43(93.5 \%)$ of them were females, live in a rural area and unable to read and write. Moreover, of the total non-adhered individuals whose reason was due to being far from home, about 18 (85.7), 16 (76.2\%) of them were married and unable to read and write. Of being busy patients, about $8(72.8 \%)$ of them were a merchant 
Table 2 Clinical Characteristics of People Living with HIVIAIDS in Eastern Tigray General Hospitals, Northern Ethiopia, 2019 $(\mathrm{N}=339)$

\begin{tabular}{|c|c|c|}
\hline Variable & Characteristics & $\begin{array}{l}\text { Frequency } \\
\text { (\%) }\end{array}$ \\
\hline Initial WHO stage & $\begin{array}{l}\text { I } \\
\text { II } \\
\text { III } \\
\text { IV }\end{array}$ & $\begin{array}{l}59(17.40 \%) \\
81(23.89 \%) \\
172(50.73 \%) \\
27(7.96 \%)\end{array}$ \\
\hline $\begin{array}{l}\mathrm{CD}_{4} \text { count when the treatment was } \\
\text { started }\end{array}$ & $\begin{array}{l}201-499 \\
\leq 200\end{array}$ & $\begin{array}{l}167(49.26 \%) \\
172(50.74 \%)\end{array}$ \\
\hline Duration of treatment in months & $\begin{array}{l}3.0-12.0 \\
12.1-24.0 \\
\geq 24.1\end{array}$ & $\begin{array}{l}38(11.20 \%) \\
81(23.89 \%) \\
220(64.89 \%)\end{array}$ \\
\hline Treatment regimen & $\begin{array}{l}\text { D4T (30) +3TC } \\
+\mathrm{NVP} \\
\mathrm{D} 4 \mathrm{~T}(30)+3 \mathrm{TC} \\
+\mathrm{EFV} \\
\mathrm{AZT}+3 \mathrm{TC}+\mathrm{NVP} \\
\mathrm{AZT}+3 \mathrm{TC}+\mathrm{EFV} \\
\mathrm{TDF}+3 \mathrm{TC}+\mathrm{EFV} \\
\mathrm{TDF}+3 \mathrm{TC}+\mathrm{NV} \mathrm{P} \\
\mathrm{TDF}+3 \mathrm{TC}+\mathrm{NV} \mathrm{P} \\
\mathrm{TDF}+\mathrm{FTC}+\mathrm{EFV} \\
\mathrm{TDF}+3 \mathrm{TC}+\mathrm{LPV} / \mathrm{r} \\
\mathrm{AZT}+3 \mathrm{TC}+\mathrm{LPV} / \mathrm{r}\end{array}$ & $\begin{array}{l}05(1.47 \%) \\
05(1.47 \%) \\
75(22.12 \%) \\
32(9.44 \%) \\
108(31.85 \%) \\
80(23.59 \%) \\
23(23.59 \%) \\
05(1.47 \%) \\
22(6.49 \%) \\
07(2.06 \%)\end{array}$ \\
\hline Current CD4 count & $\begin{array}{l}\geq 500 \\
201-499 \\
\leq 200\end{array}$ & $\begin{array}{l}167(49.26 \%) \\
\text { I6I (47.49\%) } \\
\text { II (3.24\%) }\end{array}$ \\
\hline HIV disclosure & $\begin{array}{l}\text { Yes } \\
\text { No }\end{array}$ & $\begin{array}{l}112(33 \%) \\
227(67 \%)\end{array}$ \\
\hline Substance use & $\begin{array}{l}\text { Yes } \\
\text { No }\end{array}$ & $\begin{array}{l}76(22.4 \%) \\
263(77.6 \%)\end{array}$ \\
\hline Depression & $\begin{array}{l}\text { Yes } \\
\text { No }\end{array}$ & $\begin{array}{l}88(26 \%) \\
251(74 \%)\end{array}$ \\
\hline
\end{tabular}

in their occupation. Out of the total non-adhered patients whose reason were due to fear of side effects of medication and feeling sick, 5(62.5\%), 6(75\%) of them were unable to read and write and they lack social support. Finally in multivariate logistic regression analysis only being a rural resident and lack of social support were significantly associated with non-adherence.

In this study whether barriers or facilitators of adherence were correlated or not we checked it by multicollinearity using the variance inflation factor. The variance inflation factor in this study was less than 1.5. In this study, no barriers or facilitators of adherence were collated with each other by the same individuals. Moreover, there is no more important factor than others. Because the factors are still very important even their magnitude is low.

\section{Factors Associated with Drug Adherence}

In bivariate logistic regression analysis sex, address, social support, HIV disclosure, not having depression, substance use, and WHO initial stages were significant at a P - value less than 0.2. To avoid confounding in the subsequent model, only variables with a p-value of less than 0.2 were kept in the multivariate logistic regression.

In multivariate logistic regression, the factors associated with adherence to ART were places of residence $(\mathrm{AOR}=5.13(1.63-13.44)$, social support $(\mathrm{AOR}=2.71$ (1.37-9.74), HIV disclosure (AOR=3.32 (1.43-9.24), free from depression $(\mathrm{AOR}=2.54(1.36-9.43)$ and free from substance use $(\mathrm{AOR}=3.42$ (1.67-10.87). In this study, participants who live in an urban area were 5.1 times more likely to adhere to ART. Respondents who had social support were 2.7 times more likely to adhere to ART. Patients who disclose their HIV results were 3.3 times more likely to adhere to ART. Patients who had free from depression were 2.5 times more likely to adhere to ART. Participants who had free from substance use were 3.4 times more likely to adhere to ART (Table 4).

\section{Discussion}

In this study, the magnitude of adherence to antiretroviral therapy was reported to be $74.63 \%$ (95\% CI: $71.277 .3 \%$ ). This is in line with studies done in Western Ethiopia, ${ }^{7}$ Southwest Ethiopia, ${ }^{6,9}$ Southern Ethiopia, ${ }^{10}$ Northeastern Ethiopia, ${ }^{11}$ Western Africa, ${ }^{12}$ and Sub-Saharan Africa, ${ }^{13}$ which reported $73.1 \%, 75.7 \%, 73.6 \%, 77.1 \%, 71.8 \%$, $73 \%$, and $72.9 \%$ respectively.

However, it is lower than studies done in southwest Ethiopia $(98.8 \%),{ }^{14}$ Northwest Ethiopia (88.2\%, $88.6 \%),{ }^{15,16}$ Northeast Ethiopia $(95.5 \%),{ }^{17}$ Eastern Ethiopia (85\%), ${ }^{18}$ Southeast Ethiopia $(90.8 \%),{ }^{19}$ Central Ethiopia (97\%), ${ }^{20}$ Western Africa (78\%), ${ }^{21}$ Eastern Africa $(90 \%, 94.1 \%) .{ }^{22,23}$ This difference might be due to differences in adherence measurement and a difference in sample size.

The study is higher than studies done in Northern Ethiopia $(62.3 \%),{ }^{24}$ Southern Ethiopia $(60 \%, 56 \%),{ }^{25,26}$ Eastern Ethiopia $(65 \%),{ }^{27}$ Western Africa $(62.6 \%),{ }^{28}$ Southern-central Africa $(63.81 \%){ }^{29}$ Southern Africa $(70.8 \%),{ }^{30}$ and Western Asia $(69.6 \%) .{ }^{31}$ This variation might be due to differences in adherence measurement, and socio-demographic characteristics. 
Table 3 Self-Reported Adherence (Dose, Time and Food) of HIVIAIDS People in Eastern Tigray General Hospitals, Northern Ethiopia, 2019 ( $N=339)$

\begin{tabular}{|l|l|l|}
\hline Variables & Characteristics & Frequency (Percentage) \\
\hline Self-reported dose adherence (last 7days) $(\mathrm{N}=339)$ & $\begin{array}{l}\text { Adhered } \\
\text { Not adhered }\end{array}$ & $\begin{array}{l}274(80.83 \%) \\
65(19.17 \%)\end{array}$ \\
\hline Self-reported schedule (time) adherence (last 7days) (N=339) & $\begin{array}{l}\text { Adhered } \\
\text { Not adhered }\end{array}$ & $\begin{array}{l}262(77.28 \%) \\
77(22.72 \%)\end{array}$ \\
\hline Self-reported food adherence (last 7days) (N=339) & $\begin{array}{l}\text { Adhered } \\
\text { Not adhered }\end{array}$ & $\begin{array}{l}304(89.67 \%) \\
35(10.33 \%) \\
253(74.63 \%) \\
86(25.37 \%)\end{array}$ \\
\hline
\end{tabular}

In this study, relationships were found between ART adherence and different variables. Living residence, social support, HIV disclosure, free from depression, and free from substance use, were significantly associated with ART adherence. Being an urban resident had a significant association with good adherence. This is similar to a study done in Northwest Ethiopia ${ }^{15}$ and Northern Ethiopia. ${ }^{24}$ The possible reason could be that being, not a rural resident was more educated and it may be due to the availability of access to transport. This might increase their awareness of ART adherence.
Participants who had strong social support were found more adherent to their medication than those who have poor social support. This finding is similar to a study done in West Ethiopia, ${ }^{7}$ Southwest Ethiopia, ${ }^{6,14}$ Eastern Ethiopia, ${ }^{18,27}$ Southern Ethiopia, ${ }^{25}$ Southern-central Africa, ${ }^{29}$ South Africa, ${ }^{30}$ and Sub-Saharan Africa. ${ }^{13}$ This may be due to any support from family members and friends who had direct and long-term positive influences on their ART adherence. Social support enhances the patient's self-confidence by improving uselessness and denial of medication and makes them stress-free to adhere to ART. ${ }^{7}$

Table 4 Multivariate Logistic Regression of Factors Associated with Adherence to ART Among People Living with HIV/AIDS in Eastern Tigray General Hospitals, Ethiopia, 2019 ( $N=339)$

\begin{tabular}{|c|c|c|c|c|c|c|}
\hline \multirow[t]{2}{*}{ Variable } & \multirow[t]{2}{*}{ Category } & \multicolumn{2}{|c|}{ Adherence to ART } & \multicolumn{3}{|c|}{ Odds Ratio (95\% Confidence Interval) } \\
\hline & & Yes & No & COR & AOR & P-value \\
\hline Sex & $\begin{array}{l}\text { Male } \\
\text { Female }\end{array}$ & $\begin{array}{l}89 \\
112\end{array}$ & $\begin{array}{l}67 \\
71\end{array}$ & $\begin{array}{l}0.84(0.17-0.98) \\
\text { I }\end{array}$ & $\begin{array}{l}0.76(0.12-1.07) \\
1\end{array}$ & 0.25 \\
\hline Address & $\begin{array}{l}\text { Urban } \\
\text { Rural }\end{array}$ & $\begin{array}{l}198 \\
27\end{array}$ & $\begin{array}{l}65 \\
49\end{array}$ & $\begin{array}{l}5.52(1.84-16.32) \\
1\end{array}$ & $\begin{array}{l}5.13(1.63-13.44) \\
1\end{array}$ & $0.002^{*}$ \\
\hline Social support & $\begin{array}{l}\text { Yes } \\
\text { No }\end{array}$ & $\begin{array}{l}146 \\
38\end{array}$ & $\begin{array}{l}96 \\
59\end{array}$ & $\begin{array}{l}2.43(1.24-8.62) \\
I\end{array}$ & $\begin{array}{l}2.7 I(I .37-9.74) \\
I\end{array}$ & $0.017^{*}$ \\
\hline HIV disclosure & $\begin{array}{l}\text { Yes } \\
\text { No }\end{array}$ & $\begin{array}{l}78 \\
89\end{array}$ & $\begin{array}{l}34 \\
138\end{array}$ & $\begin{array}{l}3.61(I .63-10.2 I) \\
1\end{array}$ & $\begin{array}{l}3.32(1.43-9.24) \\
1\end{array}$ & $0.009 *$ \\
\hline Depression & $\begin{array}{l}\text { No } \\
\text { Yes }\end{array}$ & $\begin{array}{l}165 \\
37\end{array}$ & $\begin{array}{l}86 \\
51\end{array}$ & $\begin{array}{l}2.63(I .43-9.82) \\
I\end{array}$ & $\begin{array}{l}2.54(1.36-9.43) \\
I\end{array}$ & $0.035^{*}$ \\
\hline Substance use & $\begin{array}{l}\text { No } \\
\text { Yes }\end{array}$ & $\begin{array}{l}159 \\
24\end{array}$ & $\begin{array}{l}104 \\
52\end{array}$ & $\begin{array}{l}3.31(1.72-10.64) \\
1\end{array}$ & $\begin{array}{l}3.42(1.67-10.87) \\
1\end{array}$ & $0.004^{*}$ \\
\hline WHO initial stage & $\begin{array}{l}\text { Stage I } \\
\text { Stage II } \\
\text { Stage III } \\
\text { Stage IV }\end{array}$ & $\begin{array}{l}35 \\
48 \\
89 \\
11\end{array}$ & $\begin{array}{l}24 \\
33 \\
83 \\
16\end{array}$ & $\begin{array}{l}\text { I } \\
\text { I.0I(I.0-1.46) } \\
1.36(1.02-2.17) \\
2.12(1.34-7.63)\end{array}$ & $\begin{array}{l}\text { I } \\
1.04(0.96-1.27) \\
1.16(0.87-1.95) \\
2.3(0.98-5.37)\end{array}$ & $\begin{array}{l}0.45 \\
0.17 \\
0.08\end{array}$ \\
\hline
\end{tabular}

Notes: 1.00 remains for reference category and *Statistically significant at $\mathrm{P}<0.05$.

Abbreviations: ART, anti-retroviral therapy; COR, crude odd ratio; AOR, adjusted odd ratio; $\mathrm{Cl}$, confidence interval. 
The finding of this study showed that study respondents who disclosed their HIV serostatus to their families were adherent to their ART medication than who did not disclose their result. This is consistent with a study that was done in West Ethiopia, ${ }^{7}$ Northwest Ethiopia, ${ }^{15}$ Eastern Ethiopia, ${ }^{18}$ Southern Ethiopia, ${ }^{26}$ Western Africa, and SubSaharan Africa. ${ }^{13}$ The reason behind may be due to, when there is no expose to their HIV status, the patients may distress to take their medications, and omission would occur. Individuals who did not disclose their HIV serostatus to his/her family or friends may put more stress on themselves and might miss their treatment. ${ }^{7}$

Patients who had free from depression were significantly related to adherence to ART medication. Similar results were reported in Southwest Ethiopia, ${ }^{6}$ Eastern Ethiopia, ${ }^{27}$ and Sub-Saharan Africa. ${ }^{13}$ These findings support the role of ART clinic health professionals in early identification of depression symptoms and early treatment.

Being free from substance use was significantly associated with adherence to ART medications. This finding was similar to a study done in Southern Ethiopia, ${ }^{10,25,26}$ Southwest Ethiopia, ${ }^{14}$ Central Ethiopia, ${ }^{20}$ Southern-central Africa, ${ }^{29}$ and Sub-Saharan Africa. ${ }^{13}$ This might be because substance users are predisposed to fail to recall their medication time and have compromised community life cycle. $^{20}$

In this study forgetting, being far from home, being busy with other things, fear of the side effect of medication, and feeling sick were the most common reasons for poor adherence to ART medications. This study was similar to the study done in Southwest Ethiopia, ${ }^{6,14}$ Southern Ethiopia, ${ }^{25,26}$ Southeast Ethiopia, ${ }^{19}$ and Southern-central Africa. ${ }^{29}$ This may be due to the patient's problems in getting the treatment access due to transportation problems, even though they were willing to take ART.

The limitations of this study were, there might be recalled bias and social desirability bias in which the result may be exaggerated. Moreover, the nature of the measurement tool which was self-reported adherence measure only.

\section{Conclusion}

The prevalence of adherence to ART in eastern Tigray was relatively low compared with the WHO standard ${ }^{32}$ and other studies. Patients' place of residence, social support, HIV disclosure, free from depression, and free from substance use were the factors associated with ART. Moreover, forgetting and being far from home was the most known justification for low adherence to ART medication. So, awareness creation for rural residence, social support, avoidance of depression and substance use should be strengthened to increase drug adherence.

\section{Implication for Practice}

Due to the fact, level of ART adherence was relatively low in this study, the health professionals should focus on the facilitators and barriers to ART adherence by giving counseling services about HIV result disclosure, the side effect of substance use, early treatment, and management of depression. Moreover, adherence can be improved by giving health education to ART users and the whole community during meetings and special conferences about the importance of social support. Most of the reason for nonadherence was due to lack of awareness, so awareness creation should be strengthened to enhance adherence to ART among HIV/AIDS patients.

\section{Abbreviations}

AIDS, acquired human immune deficiency syndrome; ART, antiretroviral therapy; HAART, highly active antiretroviral therapy; HIV, human immune-deficiency virus; HTC, HIV/AIDS testing and counseling; PLWHA, people living with HIV/AIDS; WHO, World Health Organization.

\section{Data Sharing Statement}

The data sets used and/or analyzed during the current study can be available from Teklehaimanot Tesfay Gebreagziabher on a reasonable request.

\section{Ethics Approval and Informed Consent}

This study was approved by the Institutional Review Board of Adigrat University, College of Medicine and Health Sciences, research and community service directorate office. All participants were informed about the purpose of the study, and that it was conducted in accordance with the declaration of Helsinki. Written informed consent was taken from each respondent to obtain their agreement. Participants were informed that; the right to refuse or discontinue participating in the research without any compromise in the service. No potential risk had been expected for the study participants. To maintain the confidentiality of the patients, names were not registered on the questionnaire. 


\section{Acknowledgments}

The authors are grateful to the University of Adigrat, department Nursing for giving us this chance. We would like to extend our gratitude to Adigrat ART clinic staff members, data collectors, and all adult HIV/AIDS people who participated in this study.

\section{Author Contributions}

All authors made substantial contributions to conception and design, acquisition of data, or analysis and interpretation of data; took part in drafting the article or revising it critically for important intellectual content; agreed to submit to the current journal; gave final approval of the version to be published; and agree to be accountable for all aspects of the work.

\section{Funding}

The study was funded by Adigrat University, college of medicine and Health Science, department of nursing.

\section{Disclosure}

The authors report no conflicts of interest in this work.

\section{References}

1. WHO. HIV/AIDS and mental health; 2008. Available from: https:// apps.who.int/gb/archive/pdf_files/EB124/B124_6-en.pdf.

2. UNAIDS. UNAIDS data $2019 ; 2019$. Available from: https://www. unaids.org/sites/default/files/media_asset/2019-UNAIDS-data_en.pdf.

3. Girum T, Wasie A, Worku A. Trend of HIV/AIDS for the last 26 years and predicting achievement of the 90-90-90 HIV prevention targets by 2020 in Ethiopia: a time series analysis. BMC Infect Dis. 2018;18 (1):320. doi:10.1186/s12879-018-3214-6

4. Harrigan PR, Hogg RS, Dong WW, et al. Predictors of HIV drugresistance mutations in a large antiretroviral-naive cohort initiating triple antiretroviral therapy. J Infect Dis. 2005;191(3):339-347. doi:10.1086/427192

5. (WHO) WHo. Adherence to long-term therapies. Evidence for action. Geneva; 2003;17-21. Available from: http://whqlibdoc.who.int/publica tions/2003/9241545992.pdf. Accessed July 23, 2020.

6. Amberbir A, Woldemichael K, Getachew S, Girma B, Deribe K. Predictors of adherence to antiretroviral therapy among HIV-infected persons: a prospective study in Southwest Ethiopia. BMC Public Health. 2008;8(1):265. doi:10.1186/1471-2458-8-265

7. Abadiga M, Hasen T, Mosisa G, Abdisa E. Adherence to antiretroviral therapy and associated factors among Human immunodeficiency viruspositive patients accessing treatment at Nekemte referral hospital, west Ethiopia, 2019. PLoS One. 2020;15(5):e0232703. doi:10.1371/journal. pone. 0232703

8. Commission FDRoEPC. Summary and Statistical Report of the 2007 Population and Housing Census. Ethiopia: Addis Ababa; 2008.

9. Hassen A, Mohammed Y. Antiretroviral therapy adherence level and associated factors among HIV/AIDS patients in jimma zone government health facilities, ART Clinics, South-west Ethiopia. Int $J$ Multicultural Multireligious Understanding. 2019;5(5):331-341. doi:10.18415/ijmmu.v5i5.535
10. Azmach NN. Adherence to antiretroviral therapy and associated factors among adult ARV Users in Arba Minch Hospital, Southern Ethiopia. Central African J Public Health. 2017;3(2):19-26. doi:10.11648/j.cajph.20170302.12

11. Legesse TA, Reta MA. Adherence to antiretroviral therapy and associated factors among people living with HIV/AIDS in Hara Town and its surroundings, North-Eastern Ethiopia: a cross-sectional study. Ethiop J Health Sci. 2019;29:3.

12. Prah J, Hayfron-Benjamin A, Abdulai M, Lasim O, Nartey Y. Factors affecting adherence to antiretroviral therapy among HIV/AIDS patients in cape coast metropolis. Ghana J HIV AIDS. 2018;4:1.

13. Heestermans T, Browne JL, Aitken SC, Vervoort SC, KlipsteinGrobusch K. Determinants of adherence to antiretroviral therapy among HIV-positive adults in sub-Saharan Africa: a systematic review. BMJ Global Health. 2016;1:4. doi:10.1136/bmjgh-2016000125

14. Ejigu MA, Ahmed SM, Mohammed MA. Anti-retroviral therapy adherence and its determinants among adult patients living with HIV/AIDS in South West Ethiopia: a facility-based cross-sectional study. Eur J Therapeutics. 2014;20(1):52-58.

15. Molla AA, Gelagay AA, Mekonnen HS, Teshome DF. Adherence to antiretroviral therapy and associated factors among HIV positive adults attending care and treatment in University of Gondar Referral Hospital, Northwest Ethiopia. BMC Infect Dis. 2018;18 (1):266. doi:10.1186/s12879-018-3176-8

16. Asmare M, Aychiluhem M, Ayana M, Jara D. Level of ART adherence and associated factors among HIV seropositive adult on highly active antiretroviral therapy in Debre Markos Referral Hospital, Northwest Ethiopia. J Antivir Antiretrovir. 2014;6(3):120-126.

17. Ketema AK, Weret ZS. Assessment of adherence to highly active antiretroviral therapy and associated factors among people living with HIV at Debrebrihan Referral Hospital and Health Center, Northeast Ethiopia: a cross-sectional study. HIV/AIDS. 2015;7:75.

18. Letta S, Demissie A, Oljira L, Dessie Y. Factors associated with adherence to Antiretroviral Therapy (ART) among adult people living with HIV and attending their clinical care, Eastern Ethiopia. BMC Int Health Hum Rights. 2015;15(1):1-7. doi:10.1186/s12914-015-0071-x

19. Lencha B, Hasen K, Getachew T, Abdi M, Habtamu M. Adherence to antiretroviral therapy and associated factors among people living with HIV/AIDS at Gobba Hospital, Southeast Ethiopia: an institutionalbased study. Qual Primary Care. 2015;23:336-341.

20. Chaka T, Abeya S, Adlo A, Abebe T, Hamuse S, Lencha M. Antiretroviral therapy: level of adherence and its determinants among patients on treatment in different health facilities, a crosssectional study in oromia regional state, Ethiopia. J AIDS Clin Res. 2016;7(11):1-7. doi:10.4172/2155-6113.1000629

21. Eholié S-P, Tanon A, Polneau S, et al. Field adherence to highly active antiretroviral therapy in HIV-infected adults in Abidjan, Côte d'Ivoire. JAIDS. 2007;45(3):355-358.

22. Mukui IN, Ng'ang'a L, Williamson J, et al. Rates and predictors of non-adherence to antiretroviral therapy among HIV-positive individuals in Kenya: results from the second Kenya AIDS indicator survey, 2012. PLoS One. 2016;11(12):e0167465. doi:10.1371/journal.pone. 0167465

23. Watt MH, Maman S, Golin CE, et al. Factors associated with selfreported adherence to antiretroviral therapy in a Tanzanian setting. AIDS Care. 2010;22(3):381-389. doi:10.1080/09540120903193708

24. Hailasillassie K, Etana B, Alemayehu M, Fisseha G. Factors associated with adherence of highly active antiretroviral therapy among adult HIV/AIDS patients in Mekelle Hospital Northern Ethiopia. Science J Public Health. 2014;2(4):367-372. doi:10.11648/j. sjph.20140204.30

25. Koyra $\mathrm{H}$. Adherence to antiretroviral therapy among adult persons living with HIV/AIDS in Southern Ethiopia. Int J Virol AIDS. 2018;5 (038): 10.23937. 
26. Billoro B, Mamo G, Jarso H. Adherence to antiretroviral therapy and associated factors among HIV infected patients in nigist eleni mohammed memorial general Hospital, Hossana, Southern Ethiopia. J AIDS Clin Res. 2018;9(774):2.

27. Negesa L, Demeke E, Mekonnin W. Adherence to antiretroviral therapy and factors affecting among people living with HIV/AIDS and taking antiretroviral therapy, Dire Dawa Town, Eastern Ethiopia. J Infect Dis Treat. 2017;3(1):5.

28. Potchoo Y, Tchamdja K, Balogou A, Pitche VP, Guissou IP, Kassang EK. Knowledge and adherence to antiretroviral therapy among adult people living with HIV/AIDS treated in the health care centers of the association" Espoir Vie Togo" in Togo, West Africa. BMC Clin Pharmacol. 2010;10(1):11. doi:10.1186/1472-6904-10-11
29. Mzyece P. Factors that affect adherence to antiretroviral therapy in kasama district. Int J Multi-Disciplinary Res. 2018.

30. Peltzer K, Friend-du Preez N, Ramlagan S, Anderson J. Antiretroviral treatment adherence among HIV patients in KwaZulu-Natal, South Africa. BMC Public Health. 2010;10(1):111. doi:10.1186/1471-2458-10-111

31. Motazedian N, Sayadi M, Firoozbakhtian A. Non-adherence to antiretroviral medication in Shiraz, 2014: a cross-sectional study. Afr Health Sci. 2018;18(2):384-393. doi:10.4314/ahs.v18i2.24

32. WHO. 3 Million HIVIAIDS Sufferers Could Receive ART, Release 58. Geneva; 2005.

HIV/AIDS - Research and Palliative Care

\section{Publish your work in this journal}

HIV/AIDS - Research and Palliative Care is an international, peerreviewed open-access journal focusing on advances in research in HIV, its clinical progression and management options including antiviral treatment, palliative care and public healthcare policies to control viral spread. The manuscript management system is completely online and includes a very quick and fair peer-review system, which is all easy to use. Visit http://www.dovepress.com/testimonials.php to read real quotes from published authors. 